\title{
Thermal Impact of Operating Conditions on the Performance of a Combined Cycle Gas Turbine
}

\author{
Thamir K. Ibrahim*1, M.M. Rahman ${ }^{2}$ \\ ${ }^{1,2}$ Faculty of Mechanical Engineering \\ Universiti Malaysia Pahang \\ 26600 Pekan, Pahang, Malaysia \\ *thamirmathcad@yahoo.com \\ ${ }^{2}$ Automotive Engineering Centre, Universiti Malaysia Pahang \\ 26600 Pekan, Pahang, Malaysia \\ ${ }^{1}$ Department of Mechanical Engineering, Universitiy of Tikrit, Iraq
}

\begin{abstract}
The combined cycle gas-turbine (CCGT) power plant is a highly developed technology which generates electrical power at high efficiencies. The first law of thermodynamics is used for energy analysis of the performance of the CCGT plant. The effects of varying the operating conditions (ambient temperature, compression ratio, turbine inlet temperature, isentropic compressor and turbine efficiencies, and mass flow rate of steam) on the performance of the CCGT (overall efficiency and total output power) were investigated. The programming of the performance model for CCGT was developed utilizing MATLAB software. The simulation results for CCGT show that the overall efficiency increases with increases in the compression ratio and turbine inlet temperature and with decreases in ambient temperature. The total power output increases with increases in the compression ratio, ambient temperature, and turbine inlet temperature. The peak overall efficiency was reached with a higher compression ratio and low ambient temperature. The overall efficiencies for CCGT were very high compared to the thermal efficiency of GT plants. The overall thermal efficiency of the CCGT quoted was around 57\%; hence, the compression ratios, ambient temperature, turbine inlet temperature, isentropic compressor and turbine efficiencies, and mass flow rate of steam have a strong influence on the overall performance of the CCGT cycle.
\end{abstract}

Keywords: Combined cycle, gas turbine, ambient temperature, compression ratio, power output, overall efficiency

\section{Introduction}

Many researchers have focused on improving the modeling of combined cycle gas-turbine (CCGT) power plant systems utilizing the Brayton cycle gas turbine (GT) and Rankine cycle steam turbine (ST) with air (gases) and water (steam) as working fluids to achieve efficient, reliable, and economic power generation. The current commercially available CCGT generation typically achieves a total thermal efficiency in the lower heating value range of $50-60 \%[2,3]$. Further development of simple cycle GTs, metal surface cooling technology, and high temperature bleed materials shows promise for the near-term generation of power by CCGT capable of reaching more than $60 \%$ plant thermal efficiency. Additionally, the development of GT technology as well as increases in ST cycle temperature and pressure and enhancement of $t$ he heat recovery steam

generator (HRSG) stage design is expected to achieve further improvement of the overall thermal efficiency of CCGT power plants [4, 5]. When combined, the GT Brayton cycle and the ST power plant Rankine cycle complement each other to form an efficient CCGT. The Brayton cycle has a high source temperature and rejects heat at a temperature that is conveniently used as the energy source for the Rankine cycle plant. The most commonly used working fluids for CCGT are air and steam [6-10]. Kaushika et al. [5] studied the optimum performance of a CCGT by modeling and simulation. The behavior of the GT was studied at part load. The results of a sensitivity analysis of the effect of atmospheric temperature on the GT performance are presented. The best combination of process parameters of steam leaving the steam generator which gives optimum 
performance of the CCGT was determined at part load operation. Results for the optimum values of thermal efficiency and power output together with values of the decision variables are presented [6]. Khaliq and Kaushik [7] created a simulator of the combined-cycle co-generation power plant. The simulator is built by a mathematical model for power plant modeling. The simulator is divided into two parts; the first one is a simulation of fluid flow in the power plant, and the other part is a simulation of the control system of the plant [7-10].

The purpose of this work is to evaluate the possibility of improving the overall thermal efficiency of CCGT power plants. The effects of the operating parameters on the performance of CCGT are described, and the effects of the ambient temperature compression ratio of the GT cycle on the performance of the gas, steam, and CCGT are also taken into consideration.

\section{Thermodynamic modeling}

Figure 1 shows a schematic of the CCGT and bottoming cycle using a single-pressure heat recovery steam generator (HRSG) without reheating. The GT (topping cycle) includes a single stage axial flow compressor and combustor to burn natural gas for expansion in the GT.

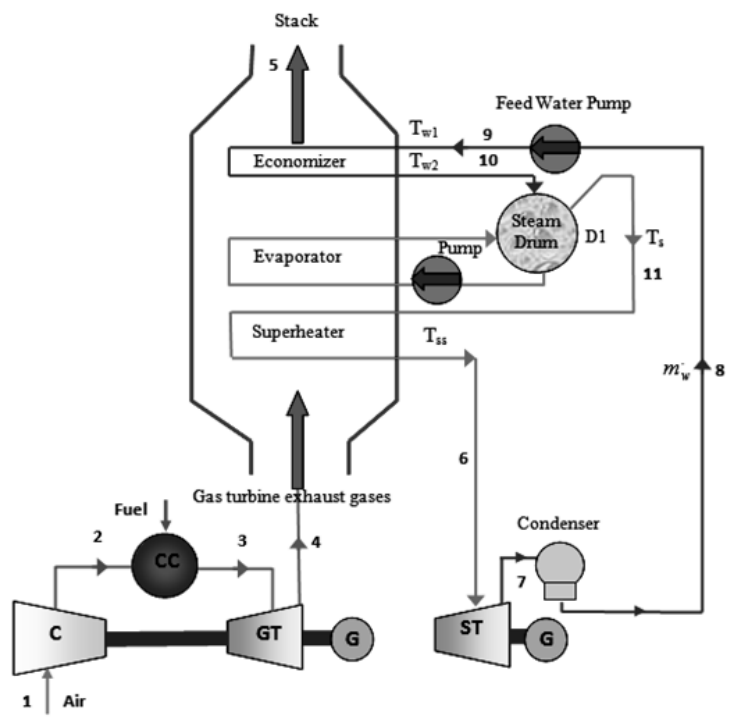

Figure 1. The schematic of the combined-cycle power plants.
Generally, the principle of the CCGT is that air is compressed by the air compressor and transferred to the combustion chamber (CC) in order to combine with fuel for producing high-temperature flue gas. Afterward, high-temperature flue gas will be sent to the GT, which is connected to the shaft of the generator for producing electricity [10]. The effluent exhaust gas temperature from the GT will decrease as it flows into the HRSG, which consists of the superheater, evaporator, and economizer. Then the HRSG supplies steam to the ST for the production of electricity. In the latter, the effluent condensate from the ST flows into a condenser, where cooling water transfers waste heat to the cooling tower. In the final stage, feed water, which is the output from the condenser, is suctioned by the feed water pump and sent to the HRSG and so on [4]. Modeling of the CCGT has been done in the following steps:

\subsection{Gas Turbine Cycle Model}

It is assumed that the compressor efficiency and the turbine efficiency are represented by $\eta_{c}$ and $\eta_{t}$, respectively. The ideal and actual processes on the temperature-entropy diagram shown in Figure 2 are represented by the solid and dashed lines, respectively [11].

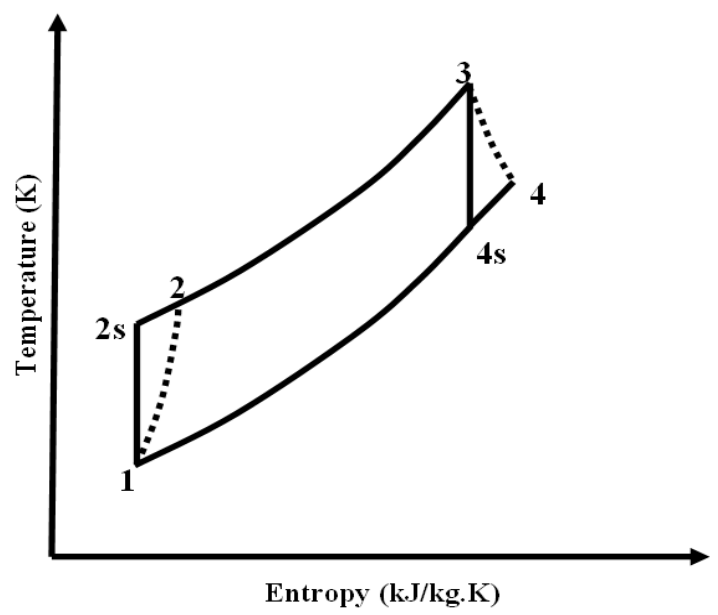

Figure 2. Temperature-entropy diagram for gas turbine.

Air Compressor model: Using the first law of thermodynamics and knowing the air inlet temperature of the compressor, the pressure ratio $\left(r_{p}\right)$, and the isentropic efficiency of the compressor, we can determine the following parameter: 
The compressor compression ratio $\left(r_{p}\right)$ can be defined as Eq. (1) [14]:

$$
r_{p}=\frac{p_{2}}{p_{1}}
$$

where $p_{1}$ and $p_{2}$ are the compressor inlet and outlet air pressures, respectively.

The isentropic efficiency of the compressor and turbine in the range of $85-90 \%$ is expressed as Eq. (2) [10]:

$$
\eta_{C}=\frac{T_{2 s}-T_{1}}{T_{2}-T_{1}}
$$

where $T_{1}$ and $T_{2}$ are the compressor inlet and outlet air temperatures, respectively, and $T_{2 \mathrm{~s}}$ is the compressor isentropic outlet temperature.

The final temperature of the compressor is calculated from Eq. (3) [12]:

$$
T_{2}=T_{1}\left(1+\frac{r_{p}^{\frac{\gamma_{a}-1}{\gamma_{a}}}-1}{\eta_{c}}\right)
$$

Therefore, these relations can be simplified by Eq. (4):

$$
R p a=\frac{r_{p}^{\frac{\gamma_{a}-1}{\gamma_{a}}}-1}{\eta_{c}} \text { and Rpg }=\left(1-\frac{1}{\left(r_{p}\right)^{\frac{\gamma_{g}-1}{\gamma_{g}}}}\right)
$$

where $\gamma_{a}=1.4$ and $\gamma_{g}=1.33$

The work of the compressor $\left(W_{c}\right)$ when blade cooling is not taken into account can be calculated as Eq. (5):

$$
W_{c}=\frac{c_{p a} \times T_{1}\left(r_{p}^{\frac{\gamma_{a}-1}{\gamma_{a}}}-1\right)}{\eta_{m} \times \eta_{c}}=\frac{C_{p a} \times T_{1} \times R p a}{\eta_{m}}
$$

where $C_{p a}$ is the specific heat of air, which can be fitted by Eq. (6) for the range of $200 \mathrm{~K}<T<800 \mathrm{~K}$ $(\mathrm{R})$, and $\eta_{m}$ is the mechanical efficiency of the compressor and turbine [15]:

$$
\begin{aligned}
& C_{p a}=1.0189 \times 10^{3}-0.13784 T_{a}+1.9843 \times 10^{-4} T_{a}^{2} \\
& +4.2399 \times 10^{-7} T_{a}^{3}-3.7632 \times 10^{-10} T_{a}^{4}
\end{aligned}
$$

Combustion chamber model: From the energy balance in the combustion chamber [18]:

$$
\begin{aligned}
& \dot{m}_{a} C_{p a} T_{2}+\dot{m}_{f} \times L H V+\dot{m}_{f} C_{p f} T_{f} \\
& =\left(\dot{m}_{a}+\dot{m}_{f}\right) C_{p g} \times T I T
\end{aligned}
$$

where $\dot{m}_{f}$ is the fuel mass flow rate $(\mathrm{kg} / \mathrm{s}), \dot{m}_{a}$ is the air mass flow rate $(\mathrm{kg} / \mathrm{s})$, LHV is low heating value, $T_{3}=T I T=$ turbine inlet temperature, $C_{p f}$ is the specific heat of fuel, and $T_{f}$ is the temperature of the fuel.

The specific heat of flue gas $\left(C_{p g}\right)$ is given by Eq. (8) [13]:

$$
\begin{aligned}
& C_{p g}=1.8083-2.3127 \times 10^{-3} T \\
& +4.045 \times 10^{-6} T^{2}-1.7363 \times 10^{-9} T^{3}
\end{aligned}
$$

After manipulating Eq. (8), the fuel air ratio $(f)$ is expressed as Eq. (9):

$$
f=\frac{\dot{m}_{f}}{\dot{m}_{a}}=\frac{C_{p g} \times T I T-C_{p a} T_{2}}{L H V-C_{p g} \times T I T}
$$

Gas turbine model: The exhaust gases temperature from the GT is given by Eq. (10).

$$
\begin{aligned}
& \mathrm{T}_{4}=T_{3}\left(1-\eta_{t} \times\left(1-\frac{1}{r_{p}^{\frac{\gamma_{g}-1}{\gamma_{g}}}}\right)\right) \\
& =T_{3}\left(1-\eta_{t} \times R p g\right)
\end{aligned}
$$


$T_{4}=T_{g 1}$, where $T_{g 1}$ is the inlet gases temperature of the HRSG.

The shaft work $\left(W_{t}\right)$ of the turbine is given by Eq. (11).

$$
W_{t}=C_{p g} \times T I T \times \eta_{t} \times R p g / \eta_{m}
$$

The net work of the GT $\left(\mathrm{W}_{\mathrm{Gnet}}\right)$ is calculated by Eq. (12):

$$
W_{\mathrm{Gnet}}=W_{t}-W_{C}
$$

The output power from the turbine $(P)$ is expressed as Eq. (13):

$$
P=\dot{m}_{a} \times W_{\text {Gnet }}
$$

The specific fuel consumption (SFC) is determined by Eq. (14):

$$
S F C=\frac{3600 f}{W_{\text {Gnet }}}
$$

The heat supplied is also expressed as Eq. (15):

$$
Q_{\text {add }}=C_{p g_{m}}\left(T I T-T_{1}(1+R p a)\right)
$$

The GT efficiency $\left(\eta_{t h}\right)$ can be determined by Eq. (16) [14]:

$$
\eta_{t h}=\frac{W_{\mathrm{Gnet}}}{Q_{\mathrm{add}}}
$$

The heat rate (HR) can be expressed as Eq. (17) $[21,22]$ :

$$
H R=\frac{3600}{\eta_{t h}}
$$

\subsection{Steam Turbine Cycle Model}

It is assumed that the ST efficiency and the pump efficiency are represented by $\eta_{s t}$ and respectively. The ideal and actual processes are represented on the temperature-entropy diagram by solid and dashed lines, respectively, as shown in Figure 3 [16].

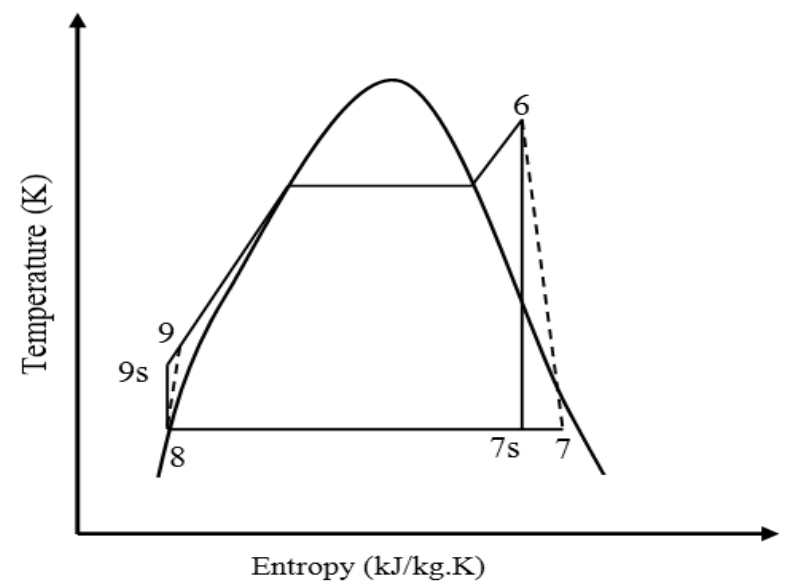

Figure 3. Temperature-entropy diagram for steam turbine plant.

Heat recovery steam generator model (HRSG): A single pressure HRSG is considered here as a common type for the CCGT plant. By applying the energy balance for gas and water in each part of the HRSG, the gas temperature and water properties, as shown in Figure 4, are calculated by solving the following equations:

The heat available of the exhaust gases from the GT can be given as Eq. (18):

$$
Q_{a v}=m_{g} \times C_{p g} \times\left(T_{g 1}-T_{g 4}\right) \times h_{1 f}
$$

where $T_{g 4}$ is the exhaust temperature of the HRSG, and $\left(h_{1 f}\right)$ is the heat loss factor, which typically ranges from 0.98 to 0.99 [17].

The superheater duty is expressed as Eq. (19):

$Q_{s h}=m_{s}\left(h_{s h}-h_{s}\right)=m_{g} \times C_{p g} \times\left(T_{g 1}-T_{g 2}\right) \times h_{1 f}$

The thermal analysis of the HRSG depends on the designed pinch point $\left(T_{p p}\right)$ and approach points ( $\left.T_{a p}\right)$. The temperature of the gas leaving the evaporator is expressed as Eq. (20): 


$$
T_{g 3}=T_{s}+T_{p p}
$$

where $T_{s}$ is the saturation steam temperature at superheated pressure. Also, the temperature of water entering the evaporator is defined as Eq. (21):

$$
T_{w 2}=T_{s}-T_{a p}
$$

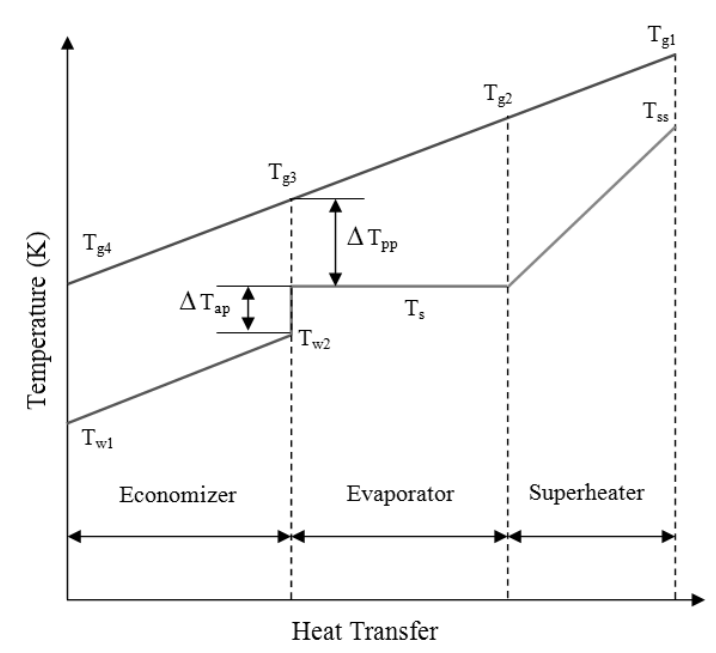

Figure 4. A typical temperature heat transfer diagram for a single-pressure HRSG combined cycle

The temperature of the hot exhaust gases exiting the HRSG can be found by considering the energy balance between states 4 and 5. Figure 1 yields:

$$
m_{s}\left(h_{s h}-h_{w 1}\right)=m_{g} C_{p g}\left(T_{g 1}-T_{g 4}\right)
$$

Steam turbine model: The steam at high pressure and high temperature that is obtained from the HRSG expands to the condenser pressure in the ST $[18,19]$. The energy balance is given as shown in Figure 3.

$$
W_{s t}=m_{s}\left(h_{6}-h_{7}\right)
$$

Condenser model: The heat rejected from the condenser is expressed as Eq. (23):

$$
Q_{\text {cond }}=m_{w}\left(h_{7}-h_{8}\right)
$$

Pump model: The condensate from the condenser is extracted by the pump and raised to the economizer pressure. The corresponding work is given by:

$$
W_{p}=m_{w} \times v_{f 9}\left(p_{s h}-p_{c}\right)
$$

Therefore, the net work of the ST power plant is:

$$
W_{\text {snet }}=W_{s t}-W_{p}
$$

The efficiency of the ST power plant is:

$$
\eta_{s t}=\frac{W_{\text {snet }}}{Q_{a v}}
$$

The overall thermal efficiency of the CCGT power plant is [23]:

$$
\eta_{\text {all }}=\frac{W_{G n e t}+W_{\text {snet }}}{Q_{a d d}}
$$

The total heating rate is:

$$
H R_{t}=\frac{3600}{\eta_{\text {all }}}
$$

\section{Results and Discussion}

The influence of parameters in terms of the compression ratio, turbine inlet temperature, airto-fuel ratio, and ambient temperature on the performance of CCGT is presented in this section. The effects of operating conditions on the power output and efficiency are obtained from the energy-balance, utilizing MATLAB10 software. Figure 5 shows the effect of the compression ratio and ambient temperature on the power output for gas, steam, and CCGT. The total power output of the CCGT increases with increases in the compression ratio and ambient temperature. This is because the power output of the steam cycle decreases with decreases in the mass flow rate of the exhaust gases, which leads to increases in the steam flow rate in the steam cycle with decreases in the compression ratio and increases in ambient temperature, as shown in Figure 6. Therefore, the total power output of CCGT increases with increases in the compression ratio, because the increases in the ST cycle are greater than the GT power output, 
and also the total power output increases with increases in the ambient temperature.

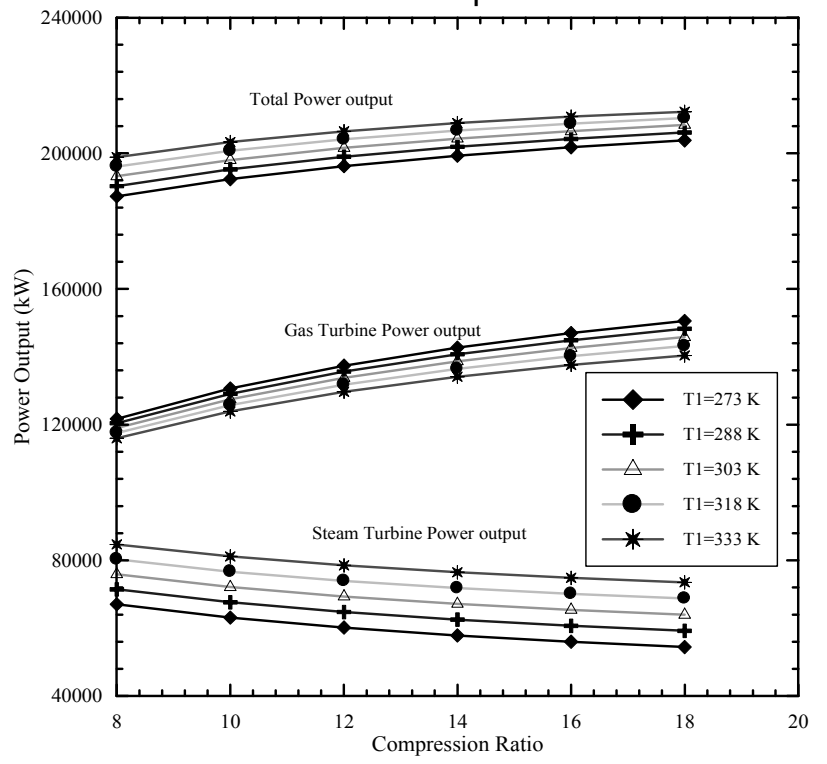

Figure 5. Comparison between simulated power output values, compression ratio and ambient temperature.

Figure 7 presents the relation between the overall efficiency of CCGT and the compression ratio for different turbine inlet temperatures and ambient temperatures. In Figure 7(a), it can be seen that the thermal efficiency increases with the compression ratio at higher turbine inlet temperatures. The deviation of overall efficiency at the lower compression ratio is not significant, but the variation at the higher compression ratio is vital for thermal efficiency. The turbine inlet temperature is crucial for the higher compression ratio. The overall efficiency at the high compression ratio increases from $54.2 \%$ to $59.4 \%$ with an increase of the turbine inlet temperature from 1100 to $1900 \mathrm{~K}$.

In Figure 7(b), the overall efficiency increases with increases in the compression ratio as well as lower ambient temperature. However, the variation in efficiency is insignificant at the lower compression ratio. The overall efficiency at the high compression ratio decreases from $58.5 \%$ to $56.4 \%$ when the ambient temperature increases from 273 to $333 \mathrm{~K}$. Figure 8 illustrates the effect of varying the compression ratio and air-to-fuel ratio on overall efficiency. The overall thermal efficiency of the CCGT decreased with increases in the air-fuel ratio because the losses with the exhaust gases increased.

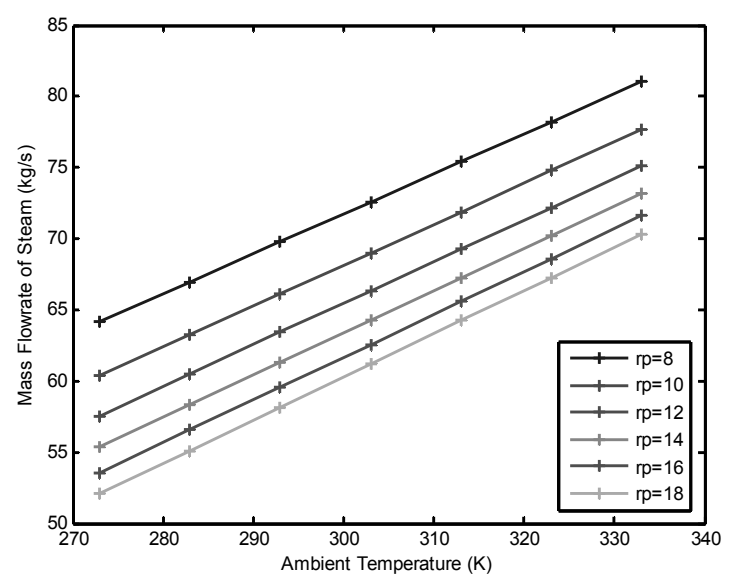

Figure 6. Effect of the compression ratio and ambient temperature on steam flow rate.

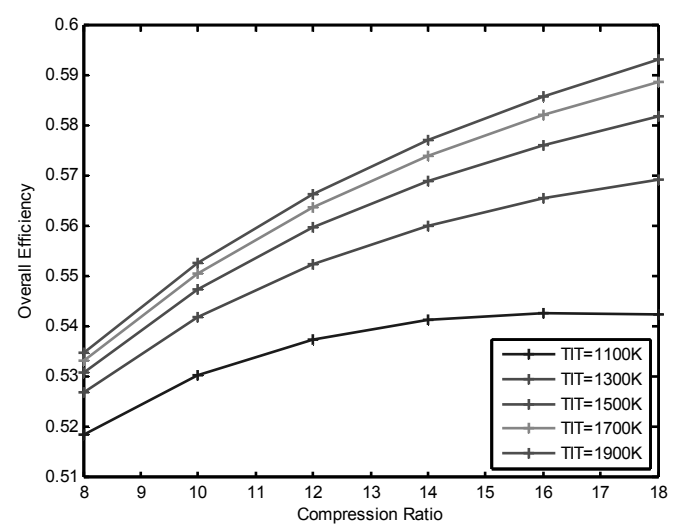

(a) Turbine inlet temperature

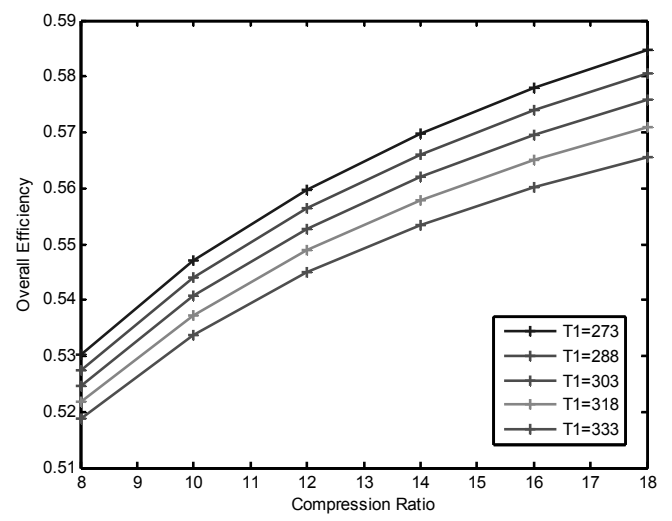

(b) Ambient temperature

Figure 7. Effect of varying the compression ratio, 
turbine inlet temperature, and ambient temperature on overall efficiency.

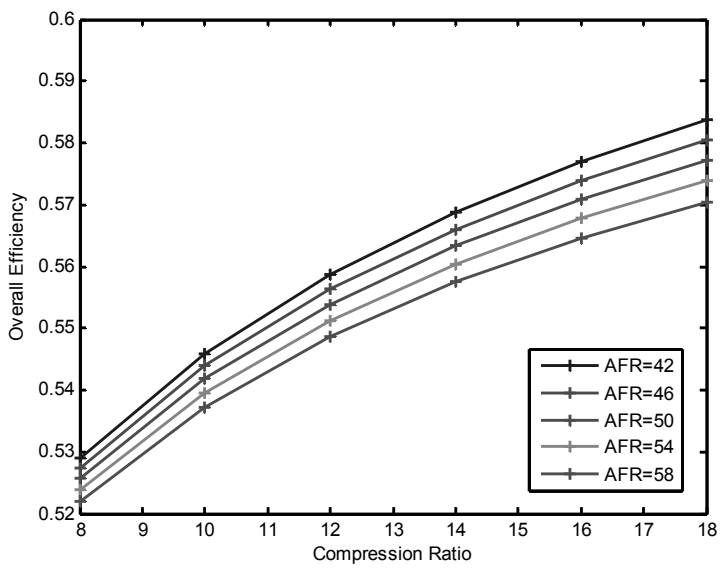

Figure 8. Effect of varying the compression ratio and air-fuel ratio on overall efficiency.

Figure 9 shows the effect of varying the compression ratio and isentropic efficiencies on the overall efficiency of the CCGT. It is observed that the overall efficiency increases with increases in the compression ratio, isentropic compressor efficiency, and turbine efficiency. However, the variation in overall efficiency is minor at the lower compression ratio while it is very significant at the higher compression ratio for both the isentropic compression and turbine efficiencies. When the compression ratio is high, the overall efficiency increases from $48 \%$ to $62 \%$ when the isentropic compressor efficiency increases from $75 \%$ to $95 \%$; however, the overall efficiency increases from $54.2 \%$ to $59 \%$ with an increase in the isentropic turbine efficiency from $75 \%$ to $95 \%$.

The performance map of a CCGT in Figure 10 shows the relation between the overall efficiency and total power output for various turbine inlet temperatures (1100-1900 K) and pressure ratios (8-20). The total power output increases as the turbine inlet temperature increases for given values; however, the turbine inlet temperature of $1900 \mathrm{~K}$ at a compression ratio of 20 yields the highest overall efficiency.

Figure 11 shows the relation between ambient temperature and overall combined cycle efficiency for different values of turbine inlet temperature. It can be observed that overall efficiency increases with increases in the turbine inlet temperature and decreases in the ambient temperature. However, the variation in overall efficiency is more significant at a higher value of turbine inlet temperature and lower ambient temperature. Figure 12 shows a comparison between the simulated power outputs of the combined cycle and simple GT versus practical results from the Baiji GT power plant. Figure 13 shows a comparison between the simulated overall efficiency of the combined cycle and the Kattha model together with the effect of different values of the turbine inlet temperature. It is clear that the overall efficiency increases with increases in the turbine inlet temperature. The simulation results were satisfactory compared with the Kattha model of the CCGT plant [24].

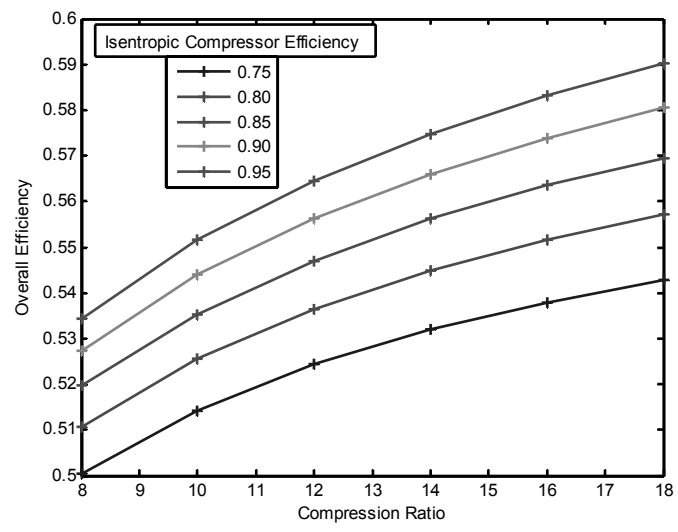

(a) Isentropic compressor efficiency

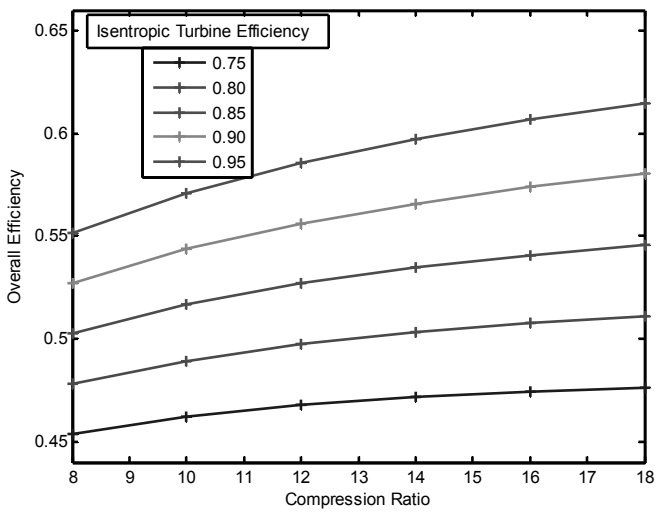

(b) Isentropic turbine efficiency

Figure 9. Effect of varying the compression 
ratio and isentropic compressor and turbine efficiencies on overall efficiency.

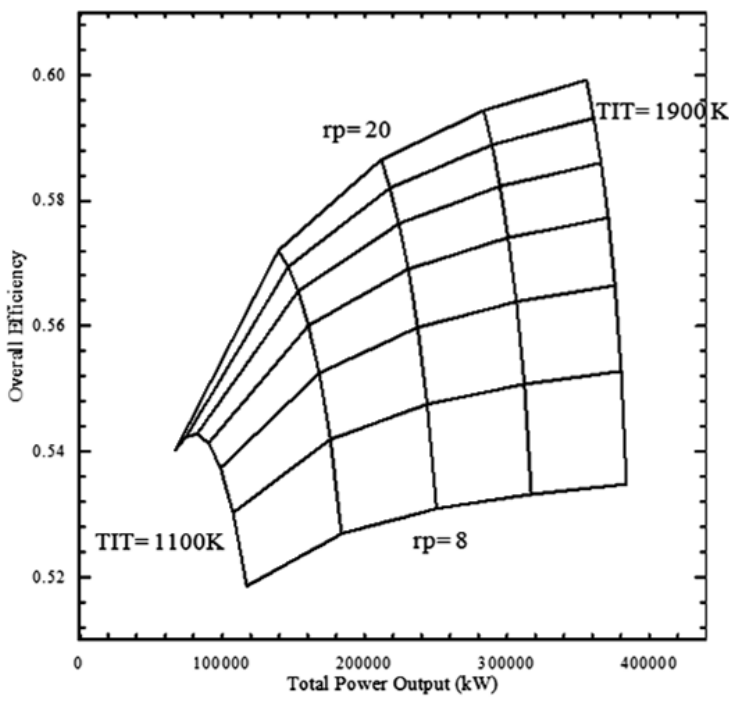

Figure 10.Variation in power with thermal efficiency for different compression ratios and turbine inlet temperatures.

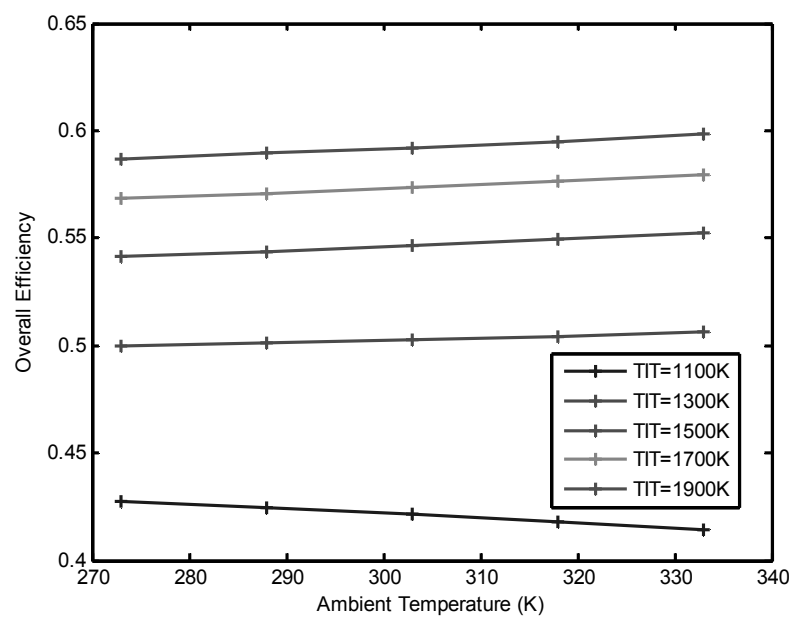

Figure 11. Effect of ambient temperature and turbine inlet temperature on overall efficiency.

Figure 14 shows the effect of ambient temperature and air-fuel ratio on the total power output of the CCGT. The total power output of the CCGT increases with increases in the ambient temperature and with decreases in the air-fuel ratio, as shown in Figure 14(a). This is because the combined cycle total power output increases with decreases in the mass flow rate for exhaust gases, which leads to increases in the steam flow rate in the steam cycle with decreases in the airfuel ratio, as shown in Figure 14(b); therefore, the total power output of the CCGT increases with increases in the ambient temperature because the increases in the ST cycle are greater than the GT power output.

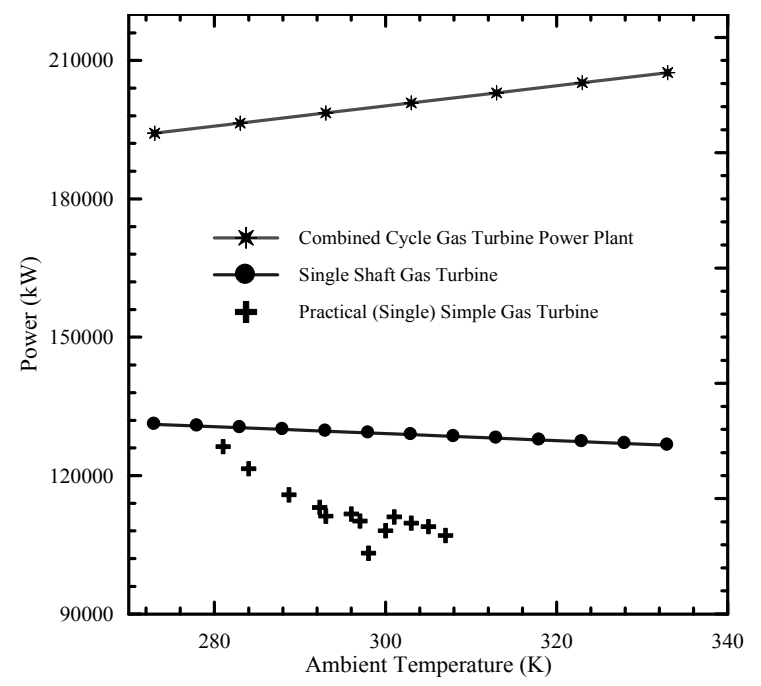

Figure 12. Comparison between simulated power outputs for the combined cycle and simple gas turbine versus practical results from the Baiji gas turbine power plants.

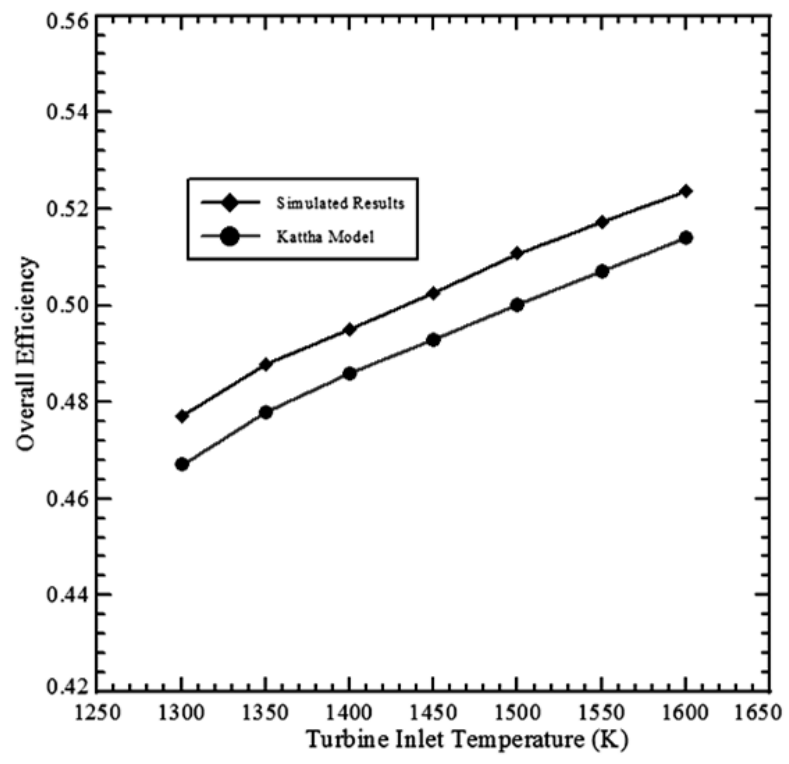


Figure 13. Comparison between simulated overall efficiency of the combined cycle and Kattha model with the effect of the turbine inlet temperature.

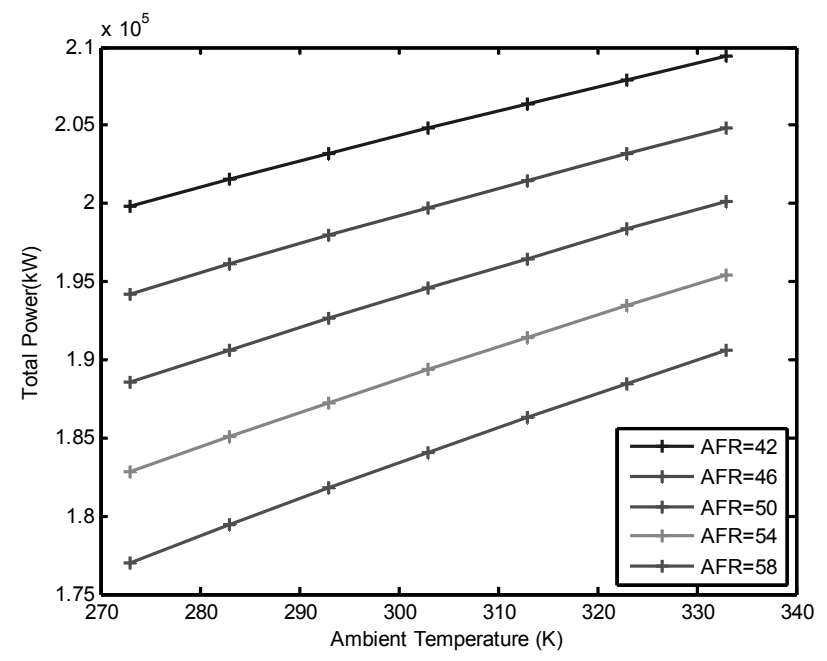

(a) Total power output

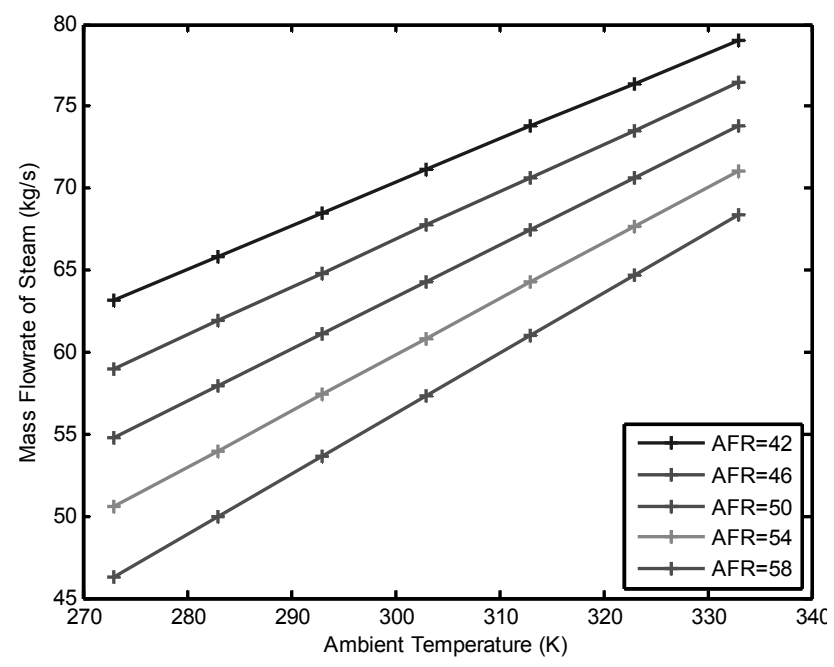

(b) Mass flow rate of steam

Figure 14. Effect of ambient temperature and air-fuel ratio on total power output and mass flow rate of steam.

Figure 15 presents the relation between the CCGT overall efficiency and the ambient temperature for different air-fuel ratios. The overall efficiency decreases with increases in the ambient temperature due to decreases in the thermal efficiency of the GT; also, the overall efficiency increases with decreases in the air-fuel ratio due to decreases in the losses with the exhaust gases. Figure 16 shows the effect of varying the ambient temperature and isentropic efficiency on the overall efficiency of the CCGT. It is observed that the overall efficiency decreases with increases in the ambient temperature and with decreases in the isentropic compressor and turbine efficiencies; however, the overall efficiency always increased with increases in the isentropic compressor and turbine efficiencies. When the ambient temperature is low, the overall efficiency increases from $52.4 \%$ to $56.2 \%$ when the isentropic compressor efficiency increases from $75 \%$ to $95 \%$, as shown in Figure 16(a). However, the overall efficiency increase from $47 \%$ to $58 \%$ with an increase in the isentropic turbine efficiency from $75 \%$ to $95 \% \%$ as shown in Figure 16(b).

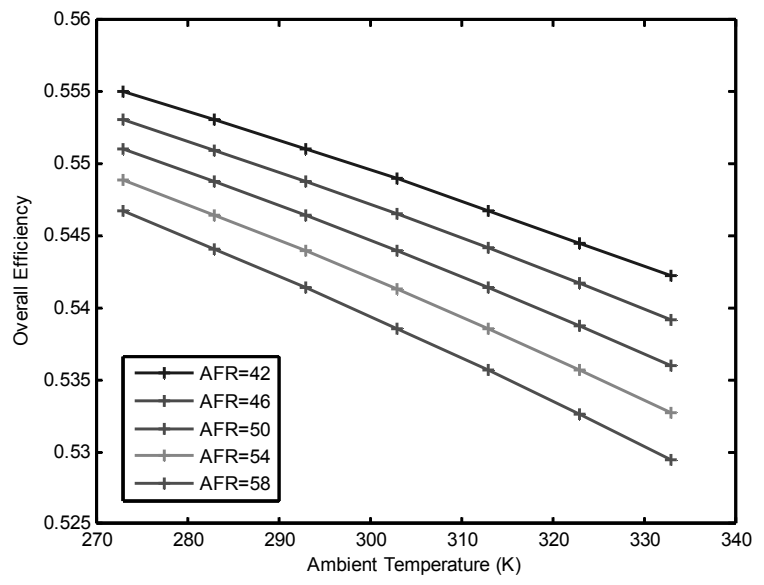

Figure 15. Effect of ambient temperature and air-fuel ratio on overall efficiency. 


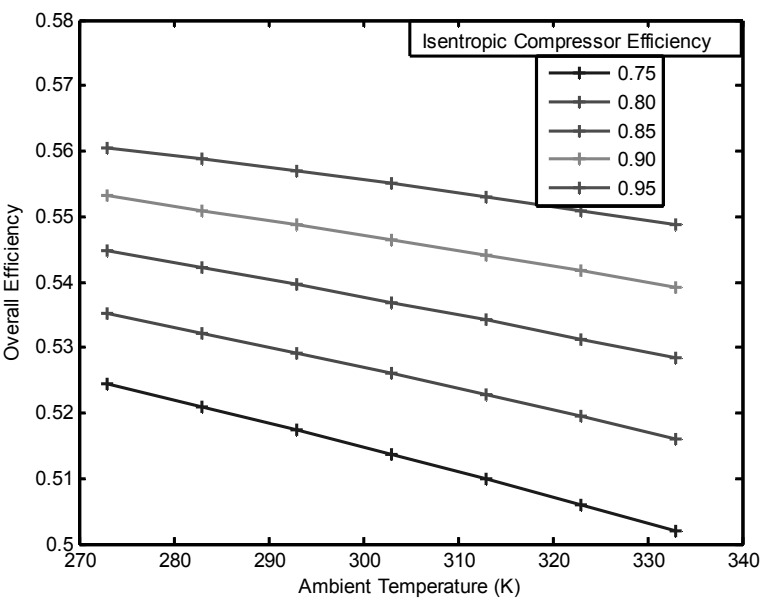

(a) Isentropic compressor efficiency

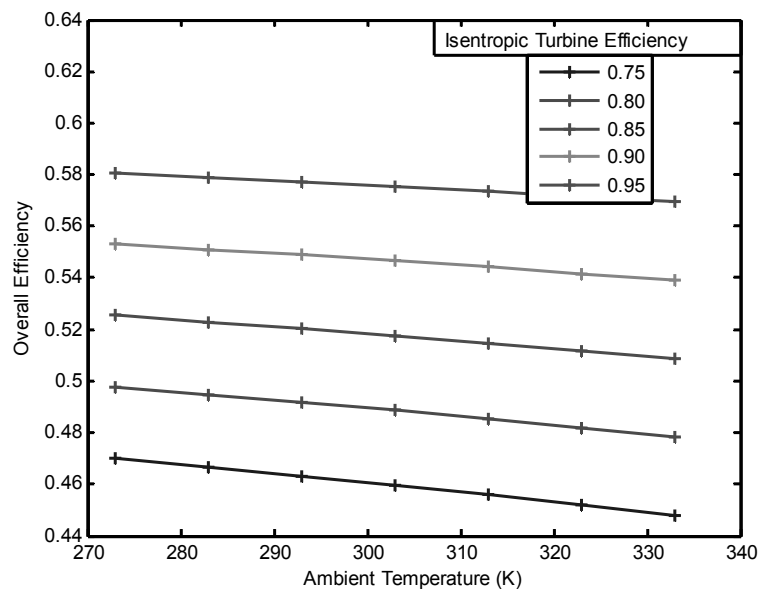

(b) Isentropic turbine efficiency

Figure 16. Effect of ambient temperature and isentropic compressor and turbine efficiencies on overall efficiency.

\section{Conclusions}

The simulated modeling results show that the compression ratio, ambient temperature, air-to-fuel ratio, and turbine inlet temperature have significant effects on the performance of the CCGT. The results are summarized as follows:

1. The compression ratios, ambient temperature, air-to-fuel ratio and isentropic efficiencies had a strong influence on the overall efficiency of the CCGT.
2. The overall thermal efficiency of the CCGT was very high compared to the thermal efficiency of the GT plants. The maximum overall thermal efficiency was about $57 \%$.

3. The overall efficiency decreases and the total power output increases linearly with increases in the ambient temperature and air-to-fuel ratio.

4. The peak overall thermal efficiency occurs at the higher compression ratio with low ambient temperature.

\section{Acknowledgements}

The authors would like to thank Universiti Malaysia Pahang for providing laboratory facilities and financial support under the Doctoral Scholarship scheme (No. GRS100332).

\section{References}

[1] T. K. Ibrahim, M. M. Rahman andA. N. Alla, Improvement of gas turbine performance based on inlet air cooling systems: A technical review. Int. J. Phy. Sci., Vol. 6, No.4, pp. 620-627,2011.

[2] M. Mostafavi, A. Alaktiwi andB. Agnew, Thermodynamic analysis of combined open-cycle-twinshaft gas turbine (Brayton cycle) and exhaust gas operated absorption refrigeration unit.Appl. Therm. Eng., Vol. 18, pp. 847-856, 1998.

[3] J. F. Mitre, A. I. Lacerda andR. F. Lacerda, Modeling and simulation of thermoelectric plant of combined cycles and its environmental impact. Therm. Eng., Vol. 4, No. 1, pp. 83-88,2005.

[4] W. Chih, thermodynamics and heat powered cycles: a cognitive engineering approach. New York:Nova Science Publishers, Inc., 2007.

[5] S. C. Kaushika, V. S. Reddya andS. K. Tyagi, Energy and exergy analyses of thermal power plants: A review. Renew. Sust. Energ. Rev., Vol. 15, pp. 1857-1872, 2011.

[6] A. G. Kaviri, M. N. M. Jaafar andT. .M. Lazim, Modeling and multiobjective exergy based optimization of a combined cycle power plant using a genetic algorithm. Energ. Convers. Manage., Vol. 58, 2012, pp. 94-103.

[7] A. Khaliq andS. C. Kaushik, Thermodynamic performance evaluation of combustion gas turbine cogeneration system with reheat. Appl. Therm. Eng., Vol. 24, 2004, pp. 1785-1795. 
[8] Razak A.M.Y., Industrial gas turbines: performance and operability. Cambridge England: Woodhead Publishing Limited and CRC Press LLC, 2007.

[9] D. S. Ashley and S. Al Zubaidy, Gas turbine performance at varying ambient temperature. Appl. Therm. Eng., Vol. 31, pp. 2735-2739, 2011.

[10] M. M. Rahman, T. K. Ibrahim, K. Kadirgama, R. Mamat andR. A. Bakar, Influence of operation conditions and ambient temperature on performance of gas turbine power plant. Adv. Mater. Res., Vol. 189-193, pp. 30073013, 2011.

[11] A. F. Al-Sayed, Aircraft propulsion and gas turbine engines. New York: Taylor \& Francis, 2008.

[12] M. M. Rahman, T. K. Ibrahim, M. Y. Taib, M M. Noor, K. Kadirgama andR. A. Bakar, Thermal analysis of opencycle regenerator gas-turbine powerplant. WASET, Vol. 68, pp. 94-99, 2010.

[13] R. K. Naradasu, R. K. Konijeti andV. R. Alluru, Thermodynamic analysis of heat recovery steam generator in combined cycle power plant. Therm. Sci., Vol. 11, No. 4, pp. 143-156, 2007.

[14] T. K. Ibrahim, M. M. Rahman and A. N. Alla, Study on the effective parameter of gas turbine model with intercooled compression process. Sci. Res. Essays, Vol. 5, No. 23, pp. 3760-3770, 2010.

[15] H. Saravanamuttoo, G. Rogers, H. Cohen andP. Straznicky, Gas turbine theory. New York: Prentice Hall, 2009.

[16] M. Ghazi, P. Ahmadi, A. F. Sotoodeh and A. Taherkhani, Modeling and thermo-economic optimization of heat recovery heat exchangers using a multimodal genetic algorithm. Energ. Convers. Manage., Vol. 5, pp. 149-156, 2012.

[17] V. Ganapathy, Waste Heat Boiler Deskbook. Indian Trail: Fairmont Press, Inc., 1991.

[18] B. Firdaus, Y. Takanobu, N. Kimio and N. Soe, Effect of ambient temperature on the performance of micro gas turbine with cogeneration system in cold region. Applied Thermal Engineering, Vol. 31, pp. 10581067, 2011.

[19] S. E. Shakib, M. Amidpour andC. Aghanajafi, Simulation and optimization of multi effect desalination coupled to a gas turbine plant with HRSG consideration. Desalination, Vol. 285, pp. 366-376, 2012.

[20] E. Godoy, N. J. Scenna andS. J. Benz, Families of optimal thermodynamic solutions for combined cycle gas turbine (CCGT) power plants. 2007, Vol. 30, pp. 569-576, 2010.

[21] S. Bracco, A. Pierfederici andA. Trucco, The wet compression technology for gas turbine power plants: Thermodynamic model. 2001,Vol. 27, pp. 699-704, 2007.

[22] M. Valdes andJ. L. Rapun, Optimization of heat recovery steam generator for combined cycle gas turbine power plants. Appl. Therm. Eng., Vol. 21, pp. 1149-1159, 2001.

[23] A. M. Bassily, Numerical cost optimization and irreversibility analysis of the triple-pressure reheat steam-air cooled GT commercial combined cycle power plants. Appl. Therm. Eng., Vol. 40, pp. 145-160, 2012.

[24] P. R. Kottha, Parametric optimization of a combined cycle. Master's Thesis, Lamar University, 2004. 
